\title{
Anaesthetic management in the surgical treatment of cicatricial tracheal stenosis
}

\author{
Volchkov V., Li V., Ivanov A., Nefedov A., Volchkova E., Boyarkin A.
}

\author{
St. Petersburg State University, Dept of Anaesthesiology \& Intensive Care; City Multifield \\ Hospital №2, Dept of Anaesthesiology \& Intensive Care, Saint Petersburg, Russian Federation
}

Goal of Study: Anaesthetic management of surgeries in patients with recurrent cicatricial tracheal stenosis (CTS) has a number of significant features. This is due to the initial disturbances of respiratory function and to the necessity of providing mechanical lung ventilation with depressurized breathing circuit during the surgical intervention.

\section{Neck computer tomography. Sagittal reconstruction}
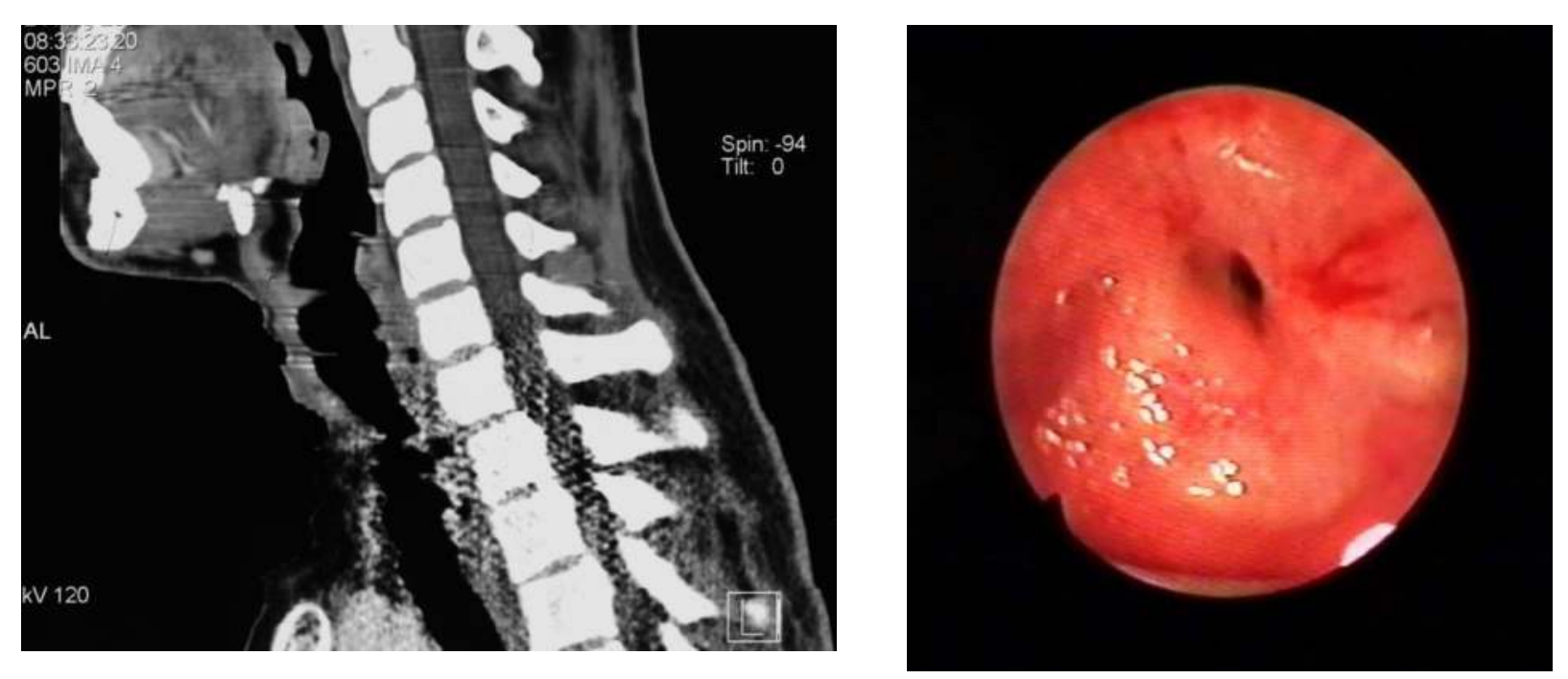

\section{Endoscopic view of CTS}

Materials and Methods: The study involved 54 patients, 40 men and 14 women, aged from 18 to 62 years. In the majority of cases CTS was caused by longterm presence of the endotracheal or tracheostomy tube (from 3 to 50 days) in the trachea after injury and trauma. Surgeries were preceded by repeated tracheal bougienages with the deployment of linear or T- shaped stents. All patients were operated on for CTS under total intravenous anaesthesia with the use of sibazon/midasolam, propofol or ketamine and arduan for myoplegia. At the stage of breathing circuit depressurization was implemented transcatheter highfrequency ( $\mathrm{f}=90-100$; group $1-\mathrm{n}=24$ ) and normalfrequency ( $\mathrm{f}=20-30$; group $2 \mathrm{n}=30$ ) artificial lung ventilation with Monsoon (ACUTRONIC).
Results and Discussion: In the preoperative period in all patients were detected initial obstructive lung function and hemodynamic respiration sufficiency disturbances, corresponding to stages 1 or 2 of respiratory failure. At the intraoperative stage was registered a slight increase of central hemodynamics parameters in both groups ( $>0.05)$. Gas exchange parameters differed apocryphally: in group $1-\mathrm{PaO} 2225 \pm 18$ and $\mathrm{PaCO} 241 \pm 12 \mathrm{~mm} \mathrm{Hg}$.; in group $2-\mathrm{PaO} 2215 \pm 12$ and $\mathrm{PaCO} 238 \pm 7 \mathrm{~mm} \mathrm{Hg}$. (p>0.05). In two patients with associated COPD at the beginning was implemented high-frequency ventilation, but because of the rise of $\mathrm{PaCO} 2$ up to $53 \mathrm{~mm} \mathrm{Hg}$., venous bypass increase up to $43 \%$ and the increase of general extravascular lung fluid up to $4.0 \mathrm{ml} / \mathrm{kg}$, ventilation mode was changed to normal-frequency and that led to the return of registered parameters in the permissible limits.

\section{Surgical intervention for CTS}

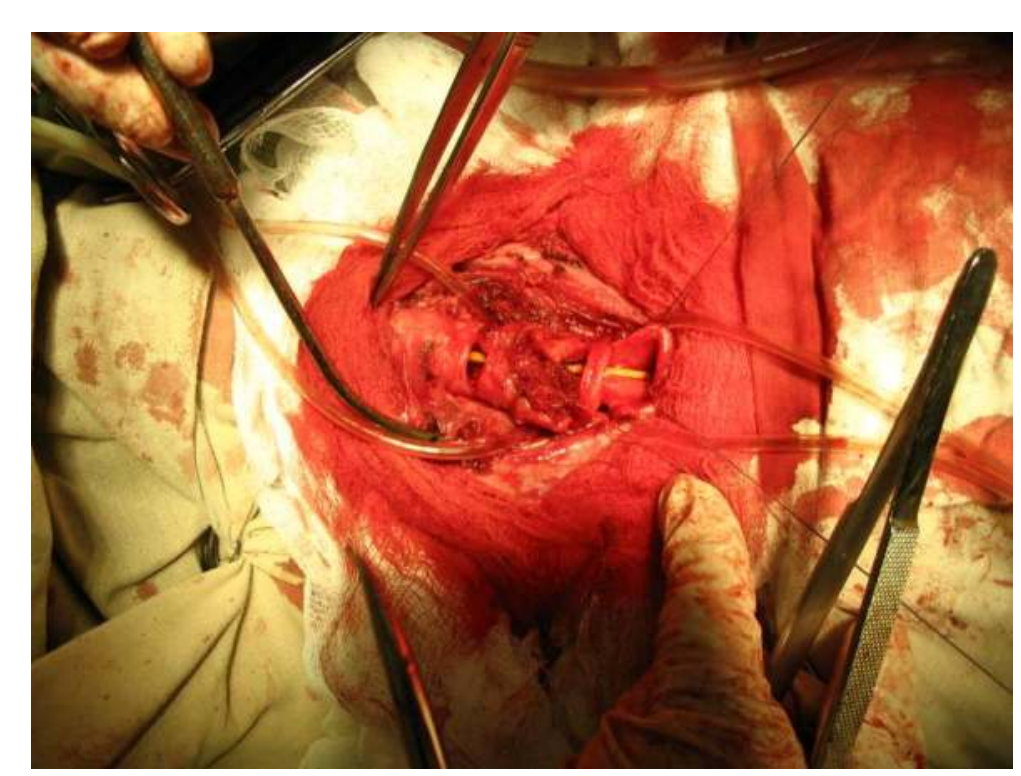

Conclusions: In patients without associated lung diseases undergoing surgical intervention for CTS, both ventilation modes with the use of total intravenous anaesthesia equally provide stable parameters of respiration and hemodynamics. In patients with COPD it is advisable to give preference to normal-frequency ventilation mode, which does not allow the intrabronchial pressure to increase significantly and create the effect of "air traps" within a reasonable operational time.

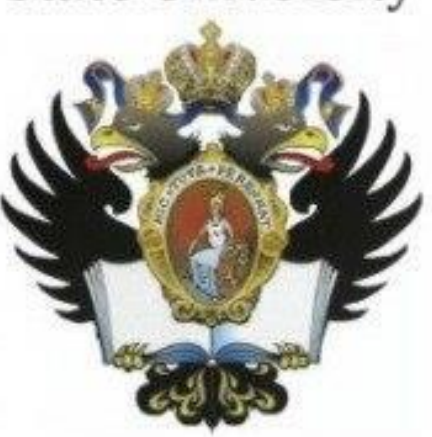

